\title{
Qualidade microbiológica da Água em RIOS de ÁREAS URBANAS E PERIURBANAS NO BAIXO AMAZONAS: O CASO DO AMAPÁ
}

\section{MICROBIOLOGIC WATER QUALITY IN URBAN AND PERIURBAN RIVERS ON LOW AMAZON RIVER - STUDY OF CASE: AMAPÁ STATE}

ALAN CAVALACANTI DA CUNHA

Instituto de Pesquisas Científicas e Tecnológicas do Estado do Amapá - IEPA. Prof. da Faculdade do Amapá-FAMAP

HELENILZA FERREIRA AlbUQUERQUE CUNHA

Universidade Federal do Amapá - UNIFAP, Ciências Sociais

ANTÔNIO CÉSAR PINHo BRASIL JÚNIOR

Universidade de Brasília - UnB, Faculdade de Tecnologia, Departamento de Eng. Mecânica

\section{LUIS ANTONIO DANIEL}

Universidade de São Paulo, Escola de Engenharia de São Carlos, Departamento de Hidráulica e Saneamento, Laboratório de Hidráulica Ambiental e Laboratório de Saneamento

\section{HARRY EDMAR SCHULZ}

Universidade de São Paulo, Escola de Engenharia de São Carlos, Departamento de Hidráulica e Saneamento, Laboratório de Hidráulica Ambiental e Laboratório de Fenômenos de Transporte

Recebido: 29/03/04 Aceito: 09/08/04

\section{RESUMO}

O presente estudo versa sobre a variação espacial-temporal de parâmetros da qualidade da água e foi realizado em quatro rios estuarinos próximos às cidades de Macapá e Santana (AP) Brasil, e trata especialmente de poluiçãao microbiológica (coliformes fecais - CF), delineada em pesquisa de campo ocorrida entre o período de setembro de 1999 a setembro de 2002. A análise espacial-temporal dos parâmetros bacteriológicos mostrou um significativo grau de comprometimento e degradação ambiental em algumas seções de coleta. A obtenção de faixas de concentração mostrou-se importante para avaliar as freqüências e distribuições estatísticas de parâmetros da qualidade da água, principalmente para indicar riscos à saúde pública e aos ecossistemas aquáticos. Finalmente, devido a quase completa ausência de informaçōes hidrodinâmica e climática sistematizada, a abordagem fundamentou-se na utilização de análise estatística. Contudo, verificou-se uma tendência de aderência dos dados a uma distribuição normal e um grau de deterioração da qualidade da água já presente nas seçôes estudadas.

PALAVRAS-CHAVES: Amazônia, rios estuarinos, poluição microbiológica, monitoramento, qualidade da água.

\section{ABSTRACT}

This study presents the spatial and temporal variability of water quality parameters in rivers of Macapá and Santana region, State of Amapá, Brazil, especially faecal coliforms (FC), being used as indicators. Laboratory and field experiments were conducted in four estuarine rivers. The experiment included five sampling locations and the research was conducted from September 1999 to September 2002. Samples were collected once a monthly. The results of analysis provided us useful information for sanitary and public health planning. In addiction, a socio-economic study of several critical areas in the watershed was carried out. The results showed high faecal coliform concentrations. The complexity of space-temporal variability of the water quality was affected by various factors, such as climatic conditions, tidal variation and human activities. This information can be used in forecasting environmental and public health risks.

\section{INTRODUÇÃO}

Estudar objetivamente qualquer característica ambiental, social, econômi- ca ou de qualquer outra natureza, na atual realidade altamente dinâmica da Amazônia, é antes de tudo um exercício de pioneirismo. Esta afirmação não preten- de ser deletéria, nem tampouco se revestir de uma falsa carapaça de valor com base em pretensas dificuldades. Ela apenas pretende deixar claro que há muitas 
lacunas de conhecimento, de monitoramento, de história científica nas regiōes que ora apresentam alteraçôes aceleradas do meio, das comunidades humanas e dos fatores de produção e agregação de valores. Independente de planejamentos e da presença da ciência, as ações "acontecem”, avançando as fronteiras das conseqüências da presença humana e alterando situações ainda não convenientemente catalogadas e quantificadas. Em outras palavras, a memória natural paulatinamente é perdida pelo simples fato de ser desconhecida, para implantar-se uma realidade já significativamente alterada.

Caminhando no sentido de registrar pelo menos momentos observados das alteraçóes mencionadas, uma vez que $o$ ambiente natural é uma realidade muitas vezes desconhecida, estudos estão sendo conduzidos para avaliar a qualidade das águas em sítios adequadamente escolhidos. Assim, em zonas estuarinas próximas às cidades de Macapá (capital do Estado) e Santana (segunda maior cidade), considerando os complexos fenômenos autodepurativos envolvidos devido às condiçóes locais, tem-se observado uma forte alteração dos níveis de concentração de coliformes fecais (CF) em alguns corpos de águas, em especial nas áreas de drenagem próximas e intercortadas por zonas urbanas e periurbanas dessas cidades. A origem das perturbações na qualidade da água deve-se, de fato, a várias causas simultâneas decorrentes de ações antrópicas e de condicionantes naturais, como o aumento da densidade populacional, a influência de marés e a precipitação pluviométrica em certas épocas do ano (ver Cunha et al, 2001, a, b). Entre as causas antrópicas destacam-se os efluentes oriundos de esgotos, os quais estão vinculados às atividades urbanas, agrícolas, portuárias e industriais. Esses poluentes comportam-se tanto de forma pontual quanto difusa, o que tem sido verificado pelo monitoramento.

Quanto às causas naturais, pode-se dizer que ainda são pouco compreendidas. Interessantemente, locais mais distantes dos centros urbanos ocasionalmente apresentam valores anormais de $\mathrm{CF}$, por exemplo (Cunha et al, 2001a). Contudo, é possível observar seus efeitos intensificadores ou mitigadores sobre a qualidade da água nos locais estudados, como é o caso da intrusão do Rio Amazonas nesses corpos de água (Cunha et al., 2000 b, c).

A constatação dos efeitos antrópicos negativos sobre os corpos de água estu- dados suscitaram a realização de estudos e investigaçôes mais detalhadas, com o objetivo precípuo de identificar e diagnosticar os impactos e, eventualmente, avaliar o seu nível. Em um horizonte mais distante, visa-se que esta informação auxilie na mitigação dos efeitos deletérios desses impactos ao meio ambiente e à saúde humana. Como desdobramento ideal da pesquisa, espera-se poder contribuir de forma mais objetiva para a gestão dos recursos hídricos e para o planejamento e gestão de bacias hidrográficas regionais. Vale sempre lembrar que a água é, nos nossos dias, uma questão estratégica.

\section{DESENVOLVIMENTO DO ESTUDO}

Os escoamentos naturais em escalas de rios envolvem fenômenos de transporte de grandezas físicas, que, por sua vez, ocorrem em regime turbulento. Essas grandezas físicas podem ser, por exemplo, sedimentos, massas de poluentes, concentração de microorganismos, massas termicamente afetadas, entre outros. Embora idealmente equacionados, os transportes turbulentos apresentam dificuldades formidáveis de quantificação para os ambientes naturais. A sua quantificação detalhada é momentaneamente uma questão sem resposta adequada, apesar de esforços nesse sentido (Schulz, 2001, 2003). Processos naturais, como a dispersão de poluentes na água, dependem essencialmente do escoamento ou da hidrodinâmica da corrente. Porém, o próprio escoamento é dependente de fatores externos a ele, como características fisiográficas, meteorológicas, físico-químicas, antrópicas, biológicas, entre outras (Cunha, 2000; Velz, 1984; McCuthcheon et al, 1989; Lung, 1993; Chapra, 1997).

Pode-se dizer que a capacidade de dispersão, diluição ou autodepuração de cada corpo de água corrente é uma característica particular e, em seu próprio contexto, altamente variável. Daí decorre a dificuldade de se estudar características generalizadoras desses processos. Velz (1984) afirma que o caráter dos recursos hídricos é dinâmico e complexo (por exemplo, ressaltam-se as regiōes estuarinas, com suas variaçōes espaciais e temporais), e que o equilíbrio estável no ambiente hidrológico é estabelecido através de interaçôes complexas entre a água, o canal de escoamento e a cobertura de vegetação, os quais são relativamente variáveis no tempo (tema também visto em
Cunha, 2001; Cunha et al., 2000a; Cunha et al., 2002a,b).

A natureza dos sistemas de drenagem é radicalmente influenciada pela fisiografia (em uma bacia razoavelmente estável, os fatores determinantes como o clima, precipitação, temperatura, velocidade do vento, pressão de vapor, radiação solar, são altamente variáveis no tempo e no espaço), que induz a variações no escoamento e na capacidade de assimilação de resíduos (Siqueira, 1996; Siqueira et al., 1997; Siqueira \& Cunha, 2001; Lung, 1993; Velz, 1984). Isto influencia nas características dos canais, os quais têm um papel maior sobre a dispersão, diluição ou autodepuração dos corpos de água.

Um aspecto relacionado indiretamente com os processos de troca e dispersivos é a disposição das águas residuárias, associada evidentemente ao impacto ambiental. Segundo Metcalf \& Eddy (1991), os regulamentos ambientais, critérios, políticas e revisões visam garantir que os impactos ambientais causados por descargas de águas residuárias tratadas ocorram em níveis aceitáveis. Esta estrutura regulamentar tem implicações na seleção do local da descarga, das estruturas de lançamento e no nível de tratamento requerido. Conseqüentemente, tratamento e disposição locais estão ligados e não podem ser considerados independentemente (Cunha et al, 2001; Velz, 1984).

Em regiōes afetadas pelas condiçōes costeiras (presente estudo), como as marés, os fenômenos de autodepuração, dispersão e diluição de poluentes microbiológicos nos corpos de água têm sido abordados com o uso de diferentes pontos de vista ou metodologias. Em uma rápida análise podemos citar cinco desses pontos de vista ou metodologias: (a) ciclo de maré, (b) modelo matemático, (c) modelo experimental, (d) abordagem estatística e (e) abordagem racional. A abordagem do prisma da maré (ciclo da maré) considera o corpo de água completamente disponível para a diluição, sendo que os resíduos fluem para o mar após cada ciclo de enchente e vazante, não retornando na próxima enchente (Velz, 1984; Cunha et al., 2002a). A hipótese decorrente deste ponto de vista pouco se aplica a realidade estudada no Amapá.

A abordagem dos modelos matemáticos aplica conclusōes da mecânica dos fluidos e dos fenômenos de transporte com diferentes graus de complexidade, dependendo do grau de detalhamento 
desejado. $\mathrm{O}$ uso de modelos matemáticos geralmente decorre da necessidade de previsões, quando a medida não está disponível. Em sua forma mais simples, utilizam-se soluções obtidas para a dispersão e transporte de poluentes em correntes (Cunha et al, 2002a). A adoção de modelos não-detalhados (unidimensionais, por exemplo) impóe o uso de hipóteses simplificadoras bastante radicais para o conjunto de variáveis existentes no caso real. A impossibilidade de considerar a superfície da água um contorno em um modelo unidimensional horizontal, por exemplo, culmina com o uso de aproximaçôes empíricas ou ad hoc para modelar a transferência de gases interfacial, por exemplo. Aproximações desse tipo são limitadas e devem ser vistas com reservas pelos projetistas. Vale mencionar que há modelos de transporte de poluentes bastante detalhados, que incorporam a resolução dos campos de velocidade e das grandezas turbulentas associadas, e que conduzem a boas previsões acerca dos fenômenos dispersivos tanto em rios, como lagos e estuários. Contudo, quanto mais um modelo se aproxima da realidade, mais informaçôes acerca dessa realidade devem ser fornecidas para que os resultados correspondam a boas previsôes (dados geográficos, cobertura vegetal, etc).

As complexidades inerentes ao uso dos modelos matemáticos e experimentais têm talvez afastado os pesquisadores que necessitam de resultados mais imediatos, resultando no surgimento do uso da abordagem dita estatística. Em princípio, não se definem ou formulam relaçôes fundamentais governantes, confiando-se essencialmente nos resultados de uma análise estatística adequada de dados coletados acerca da qualidade da água observada (Cunha et al., 2002b; Velz, 1984). A utilidade de tal abordagem está na interpolação possível dentro da estrutura de dados disponível, uma vez que não se extraem imediatamente conclusões gerais, por não haver vínculo construído a priori com os fundamentos dos processos relevantes (como a hidrodinâmica, ou o clima, fatores antrópicos, etc., na construção de um modelo). Não obstante, conclusões referentes à distribuição probabilística (funções de densidade de probabilidade, por exemplo) podem ser extraídas de massas de dados, podendo constituir uma característica de fato do fenômeno. Exemplos podem ser vistos em Lakhan (1989), que demonstra que parâmetros físicos como as elevaçóes de ondas apresentam uma distribuição de Rayleigh; as faixas ou amplitudes de marés são normalmente distribuídas; velocidades de corrente ao longo da costa são exponencialmente distribuídas; e o tamanho da partícula do sedimento pode ser distribuído por uma log-normal. Esta é a abordagem mais utilizada no presente estudo em decorrência das dificuldades anteriormente mencionadas.

Finalmente, menciona-se, no contexto do estudo de áreas costeiras, a abordagem dita racional, que busca contornar as complexidades inerentes às abordagens com uso de modelos matemáticos incorporando informaçôes decorrentes de estudos intensos no local. Visa-se que as características dinâmicas sejam mensuradas da forma mais completa possível, como os efeitos cíclicos de variação de marés e dos parâmetros da qualidade da água, principalmente a salinidade, em cada trecho de rio estudado. Evidentemente consideram-se os fatores e parâmetros reconhecidos como relevantes nos processos e as modificaçôes associadas com a translação da maré e intrusão da frente de concentração da água salgada nas regióes estuarinas (Velz, 1984; Lung, 1993). No presente estudo também buscou-se caminhar no sentido de uma abordagem racional, coletando dados dos corpos de água, as vazôes em um ciclo de maré (obtidas com equipamento $\mathrm{ADCP}^{1}$ ) no Igarapé da Fortaleza, Vila Nova e Matapi. $\mathrm{O}$ equipamento foi gentilmente cedido pela UnB/ANA.

\section{METODOLOGIA E PESQUISA DE CAMPO}

Durante a execução e planejamento dos trabalhos de campo e laboratório (IEPA/SEMA) verificou-se localmente a ampla variação espaço-temporal da concentração de poluentes microbiológicos, que é governada principalmente por funções de força climáticas, de marés e antrópicas. A Figura 1 mostra detalhes da área estudada. Os pequenos círculos no mapa indicam os locais de coleta de amostras de água, onde estão compreendidos trechos de quatro bacias hidro- gráficas estudadas: Paxicu, Fortaleza, Matapi e Vila Nova.

As concentraçóes de coliformes fecais foram determinadas em laboratório de análise da qualidade da água (SEMA/IEPA) pela técnica de tubos múltiplos. Os trechos escolhidos para o monitoramento foram determinados por fatores tais como uso da terra, riscos ambientais, influência de tributários derivados de corpos de águas poluídos e não poluídas em áreas urbanas e periurbanas próximas de Macapá e Santana (Cunha et al., 2000; Cunha et al., 2001a,b). O período da investigação abrangeu desde o mês de setembro de 1999 até setembro de 2002, configurando-se em 34 campanhas já realizadas (duas perdidas). As campanhas foram normalmente realizadas na última semana do final de cada mês, no horário entre 8:00 - 14:00h, geralmente nas segundas ou terças feiras, independente de maré, clima ou condição ambiental, com o objetivo de obter as séries históricas. A logística de transporte indicou que as distâncias entre os pontos de coleta foram: máxima $22 \mathrm{~km}$ e mínima $0,5 \mathrm{~km}$ (ver Figura 1).

As componentes sócio-econômicas das populações ribeirinhas foram também consideradas importantes no processo para avaliar a sensibilidade das populações ribeirinhas quanto a poluição dos recursos hídricos. Para tanto, realizou-se levantamentos sobre o perfil das atividades antrópicas consideradas mais relevantes para as análises no contexto da pesquisa. Parte deste estudo (bacia do Igarapé da Fortaleza) está resumida na Tabela1.

Foram indicadas as quatro principais zonas estudadas na Bacia do Igarapé da Fortaleza (tema de estudo de Cunha \& Couto, 2003). Esta foi considerada a área mais impactada pela poluição microbiológica, por se localizar entre as cidades de Macapá e Santanta e foi destacada para indicar os setores mais atuantes em pelo menos uma bacia hidrográfica estudada.

\footnotetext{
${ }^{1}$ Acoustic Doppler Current Profiler. O equipamento transmite ondas sonoras através da água. As partículas, carregadas pela corrente de água em diferentes profundidades refletem o som de volta para o equipamento, que escuta o eco através de seus sensores. O retorno do som de partículas a diferentes profundidades faz com que os sensores do ADCP, também reconheçam diferentes profundidades. Isto faz com que o equipamento construa um perfil vertical da coluna d'água. O movimento das partículas d'água causa mudança na freqüência do eco. O ADCP mede essa mudança, denominada de efeito dopller como uma função da profundidade para obter a velocidade de corrente em até 128 posições diferentes na coluna d'água. Para exemplificar, caso utilizássemos os procedimentos convencionais para a realização dessa tarefa, necessitaríamos de 128 correntômetros ou 128 molinetes trabalhando sincronizadamente (Sousa e Kosuth, 2001).
} 


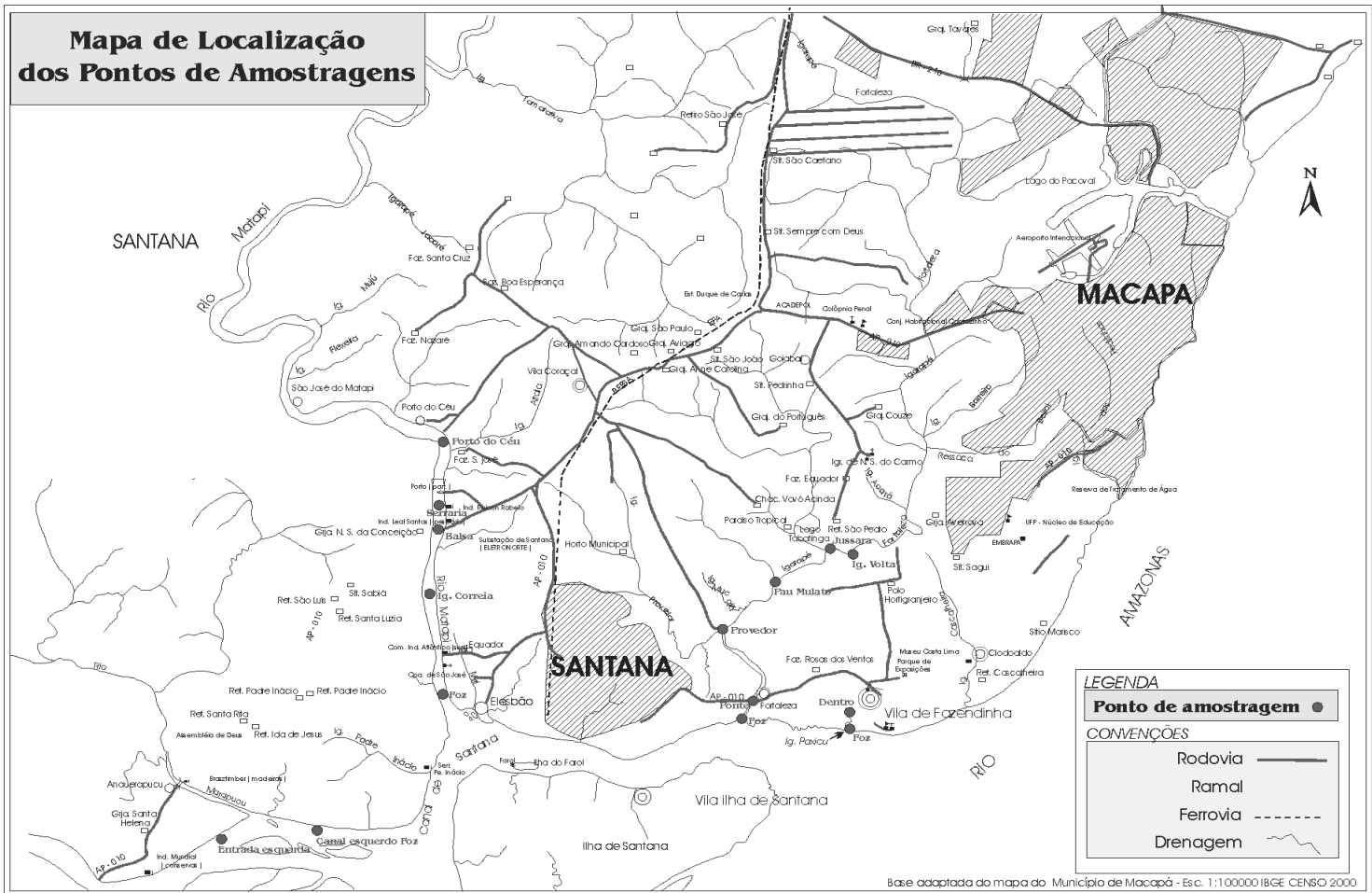

Figura I- Mapa da região estudada, indicando os I5 pontos de coleta no período de setembro de 1999 a setembro de 2002. Fonte Cunha et al. (200 Ia)

Tabela I - Zoneamento ecológico e econômico na micro-bacia do Igarapé da Fortaleza. Definição de setores importantes para o estudo segundo a visão da própria comunidade e órgãos institucionais participantes do DRP-2003 Fonte: Cunha \& Couto (2003)*

\begin{tabular}{|c|c|c|}
\hline Zona & Características sócio econômicas & Características ambientais \\
\hline Provedor-Ponte & - Maior concentração populacional e atividades urbanas. & $\begin{array}{l}\text { - Área ocupada e urbanizada desordenadamente. } \\
\text { - Trecho de mata de terra-firme atrás do Colégio } \\
\text { da Fortaleza. } \\
\text { - Altos níveis de poluição do Igarapé Provedor. } \\
\text { - Pequena criação de búfalos. }\end{array}$ \\
\hline $\begin{array}{l}\text { REBIO da } \\
\text { Fazendinha }\end{array}$ & $\begin{array}{l}\text { - Extração de madeira e coleta de açaí. } \\
\text { - Porto } 24 \text { horas. } \\
\text { - Maior parte das atividades rurais da população (pesca, } \\
\text { extração de madeira e palmito e coleta de açaí) é } \\
\text { realizada fora da reserva. } \\
\text { - A ocupação se dá pela atração dos benefícios dos } \\
\text { equipamentos e serviços urbanos. }\end{array}$ & $\begin{array}{l}\text { - Floresta de várzea. } \\
\text { - Área protegida legalmente. }\end{array}$ \\
\hline $\begin{array}{l}\text { Calha do Igarapé } \\
\text { Fortaleza e afluentes }\end{array}$ & $\begin{array}{l}\text { - Pecuária. } \\
\text { - Pequena pesca artesanal de camarão e peixe. } \\
\text { - Manejo de açaizal. } \\
\text { - Presença de produtores rurais dedicados a roça de } \\
\text { cana, milho, macaxeira e sistemas agro-florestais com } \\
\text { açaí, cupuaçu, goiaba. } \\
\text { - balneários. }\end{array}$ & $\begin{array}{l}\text { - Presença de várzea e mata de terra-firme. } \\
\text { - Nas cabeceiras de braços do Ig. - Fortaleza } \\
\text { ocorrem pequenos igapós que servem como } \\
\text { berçários de peixes. } \\
\text { - Na terra firme são feitas construções. } \\
\text { - A mata ciliar tem sido afetada para implantação } \\
\text { de pastos e balneários e extração predatória de } \\
\text { palmito de açaí. }\end{array}$ \\
\hline $\begin{array}{l}\text { Lagoa dos Índios e } \\
\text { Ressacas de Cima } \\
\text { (Congos, Zerão, } \\
\text { Buritizal e Infraero) }\end{array}$ & $\begin{array}{l}\text { - Lago utilizado como área de lazer, pesca artesanal e } \\
\text { banho } \\
\text { - Concentração de comércios e grande número de } \\
\text { funcionários públicos. } \\
\text { - Existência de uma comunidade remanescente de } \\
\text { quilombo com aproximadamente } 50 \text { famílias, } \\
\text { organizadas em } 2 \text { associações. } \\
\text { - Produção de farinha, milho e feijão, para } \\
\text { comercialização. }\end{array}$ & $\begin{array}{l}\text { - Marcado pela lagoa e ressacas. } \\
\text { - Alta concentração de infra-estrutura urbana, } \\
\text { com residenciais de classe média na lagoa e } \\
\text { construçóes irregulares pela classe baixa nas } \\
\text { ressacas. } \\
\text { - Resquícios de mata de terra firme no entorno } \\
\text { das ressacas. } \\
\text { - Altos níveis de poluição. } \\
\text { - Ausência de fiscalização ambiental. }\end{array}$ \\
\hline
\end{tabular}

* Dados ainda não publicados - DRP-SETEC (2004 - prelo) 


\section{RESULTADOS E DISCUSSÃO}

A Figura 2 mostra a variabilidade espacial-temporal da concentração de $\mathrm{CF}$ nas áreas analisadas. A flutuaçẫo da concentração tem sido determinada principalmente por variações e dinâmica de marés. Contudo, o padrão de comportamento tende a se tornar mais complexo com o efeito de precipitações pluviométricas, do período de janeiro a abril. Observa-se também que a concentração na escala logarítmica ultrapassa freqüentemente o nível máximo permitido para rios Classe 2, de acordo com a Resolução 20 do CONAMA (isto é, log $\mathrm{CF}=3,0)$. O eixo temporal indica o número da coleta a partir de setembro de 1999, mês 1 . O último mês, 36, indica a coleta de setembro de 2002.

O gráfico da Figura 3 permite avaliar a distribuição estatística da concentração de CF conjuntamente para todos os pontos de coleta. A partir de uma breve observação, verifica-se que, partindo de $\mathrm{Y} \approx 3,0 \mathrm{em}$ direção à curva ajustada $\mathrm{e}$ desta até o eixo $X$, há uma probabilidade de pelo menos $55 \%$ de a concentração média global ser igual ou superior a 1000 (ou seja, $\log \mathrm{CF} \approx 3,00$ ), indicando os riscos associados a estes valores acima do permitido por lei. Simplificando a interpretação meramente numérica mencionada, verifica-se que, globalmente, já há um grau de comprometimento da qualidade da água, tanto espacialmente quanto temporalmente.

A Figura 3 demonstra ser possível registrar de forma adequada o momento presente das condiçōes de qualidade de água em uma região ainda carente desses dados. A série histórica gerada para os dados de CF e expressa na Figura 3 incorporou, com confiabilidade bastante marcante $\left(\mathrm{R}^{2}=0,95\right)$, as possíveis influências sobre a variabilidade de concentração, mostrando ainda que os dados são bem ajustados a uma curva normal. Este resultado é relevante, porque se mostra que é possível realizar avaliações globais em regiōes extensas com a presente metodologia, ou seja, utilizando uma ferramenta estatística simples, sendo possível "filtrar" as possíveis interferências da variabilidade dos fatores que interferem na freqüência, distribuição e nível de concentração espacial-temporal da poluiçãoo microbiológica nas áreas estudadas.

A Figura 4 representa um conjunto de dados que mostra o comportamento

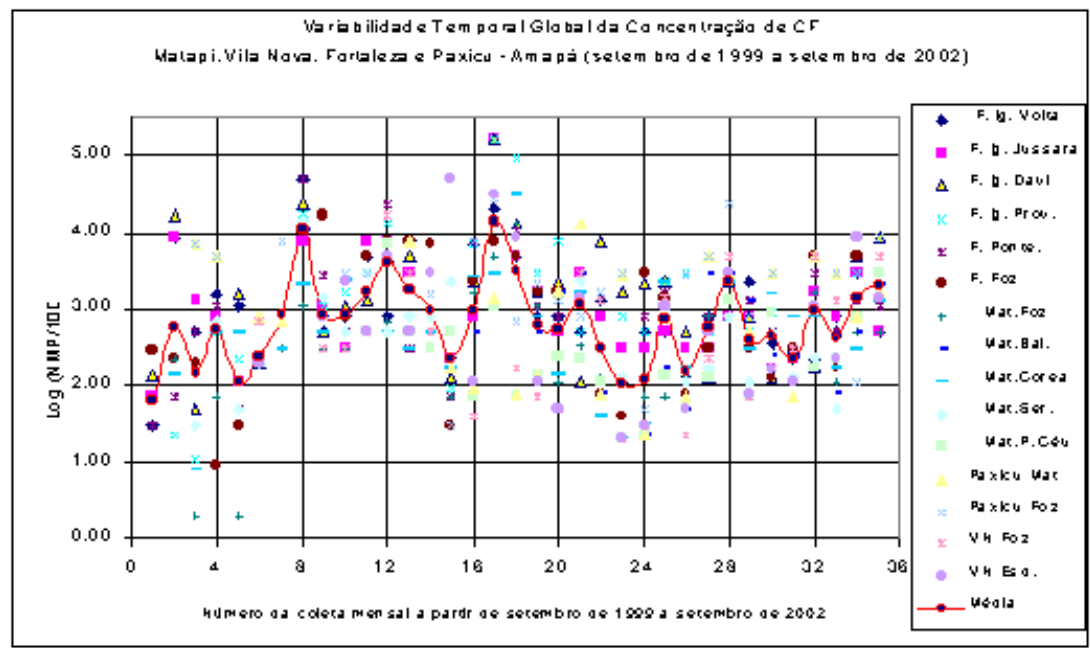

Figura 2 - Variabilidade espaço-temporal da concentração de CF. Os pontos representam cada coleta mensal nos quinze pontos monitorados durante três anos (NMP CF/100mL da amostra)

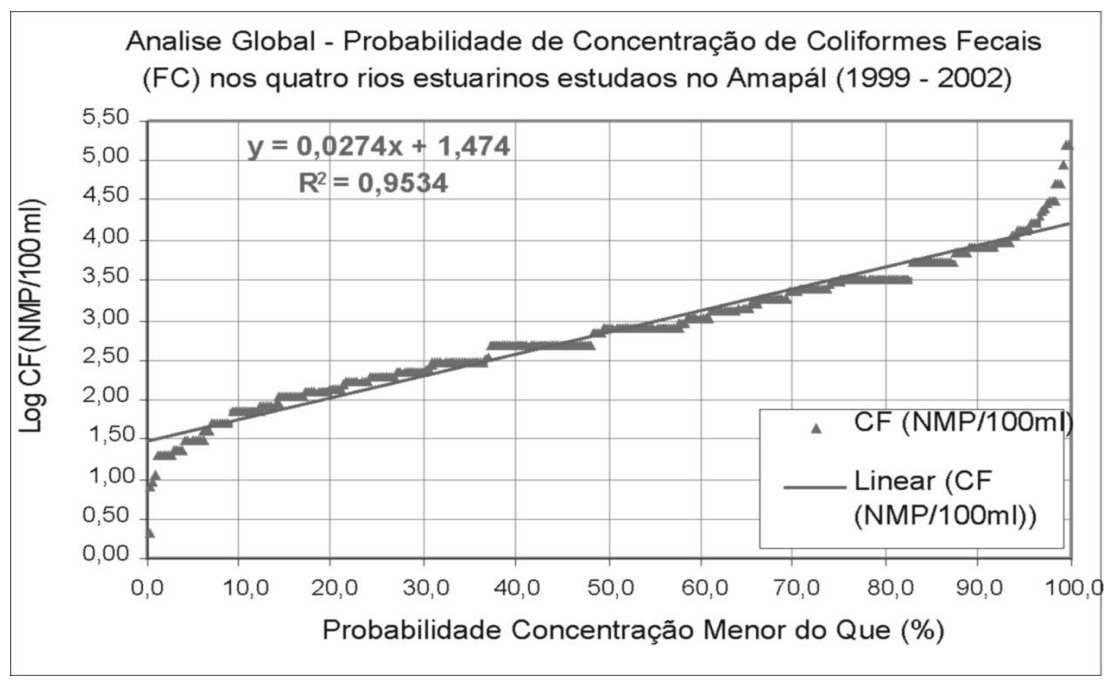

Figura 3 - Curva de probabilidade da concentração global média dos quinze pontos monitorados conjuntamente (log NMP CF/ $100 \mathrm{~mL}$ da amostra).

Verifica-se o forte ajuste à normalidade, indicado pelo coeficiente $\boldsymbol{R}^{2}$. Observe os pontos acima do valor 3,0 permitido pelo CONAMA, rio classe -2

temporal de parâmetros hidrodinâmicos (vazão e velocidade média, obtidas com o uso do $\mathrm{ADCP}$ ) e de qualidade da água (coletas analisadas em laboratório) para o período de tempo de um ciclo de maré, no Igarapé da Fortaleza. Nessa figura observa-se a influência evidente da maré na vazão e na velocidade, bem como na turbidez e na condutividade. Os demais parâmetros, nesta coleta de dados, mantiveram-se relativamente inalterados.

A Figura 5, por sua vez, mostra a interessante correlação observada entre o comportamento das precipitações (uma variável climática) e a concentração de $\mathrm{CF}$ na área estudada.

Verifica-se que é possível, mesmo em um contexto algo limitado para pesqui- sas ambientais, observar o comportamento hidrodinâmico juntamente com a avaliação da qualidade da água em um ciclo completo de maré, conforme mostrado para o Igarapé da Fortaleza. A variabilidade de alguns parâmetros de qualidade da água, em conjunto com a invariabilidade de outros, demonstra que o ambiente abordado é complexo. Mas os resultados demonstram, sobremaneira, que estudos convenientemente conduzidos, ainda que simples, permitem gerar dados que mostram a influência de fatores naturais, sobre a qualidade da água, como o clima e as marés, e de fatores antropogênicos.

\section{CONCLUSÕES}

Foi realizado um estudo para determinar a intensidade e as faixas de varia- 


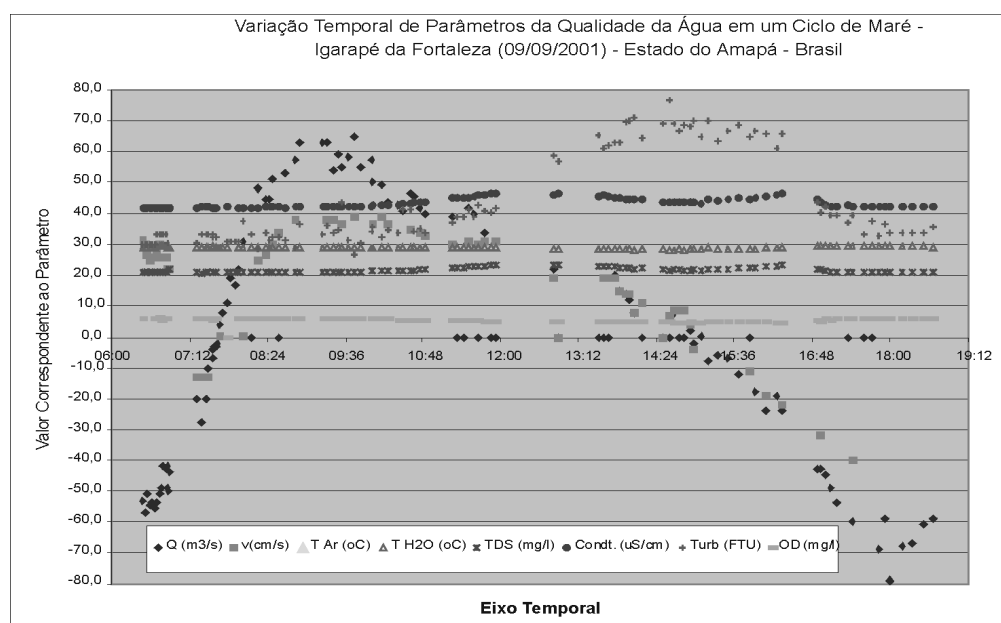

Figura 4 - Comportamento da variação temporal de parâmetros hidrodinâmicos (vazão e velocidade médias) e de qualidade da água no Igarapé da Fortaleza. Neste experimento não constou CF

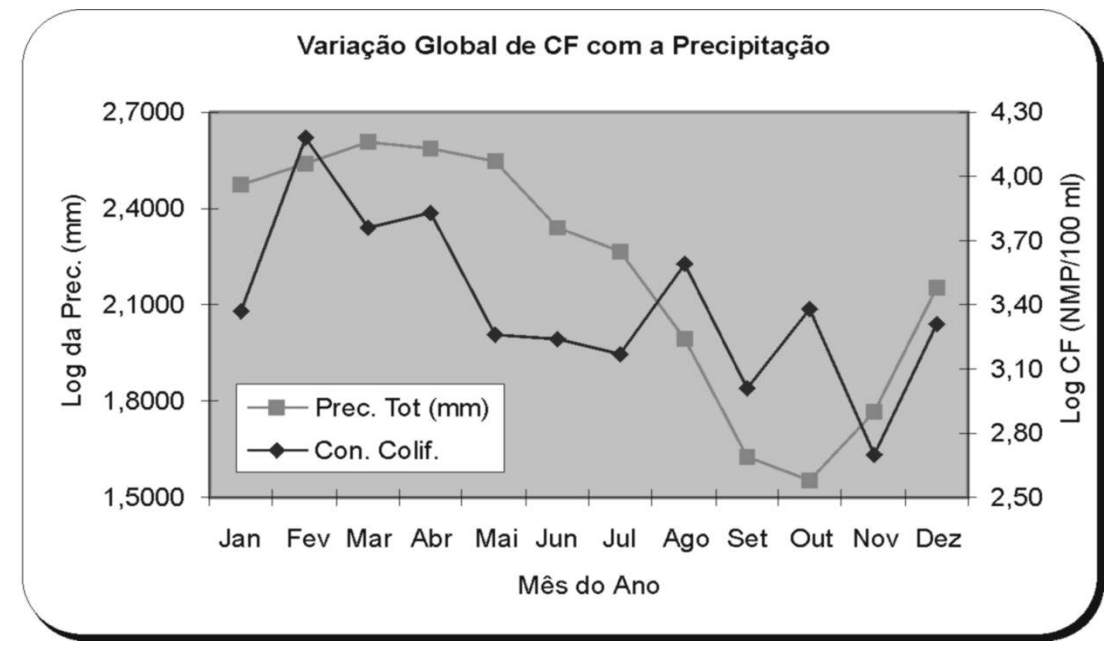

Figura 5 - Comportamento da concentração global média de CF em função das normais climatológicas de Macapá (Fonte: Site INMET-2003). Observam-se os elevados níveis de CF com a presença de chuvas

ção de concentração de coliformes fecais e de alguns parâmetros de qualidade da água em rios estuarinos próximos de áreas urbanas e periurbanas de Macapá e Santana. As concentraçōes de CF foram utilizadas como indicadoras de poluição e respectivo grau de interferência antrópica que provavelmente tem resultado no desequilíbrio dos ecossistemas aquáticos estudados, principalmente causados pelos efeitos de lançamento de esgotos e resíduos domésticos em corpos de água superficiais.

Uma primeira informação relevante relacionada ao levantamento desta série histórica é a possibilidade de verificação (quantificação) do nível de variabilidade das concentrações de CF ao longo do tempo e do espaço (Figura 2). Uma segunda informação relevante é que toda correntes preferenciais do escoamento. Ao mesmo tempo, essas plumas seguem uma "mão dupla de movimento" (por assim dizer) governada pelas forças de marés e, ocasionalmente, das precipitaçôes pluviométricas (Figura 5). Entre outros fatores eventualmente ainda não descritos, esses aqui mencionados contribuem para a explicação dos elevados níveis de CF nestes corpos de água, aparentemente tão saudáveis a olho nú.

Como já mencionado, os resultados servem de base para a tomada de decisōes em regiōes semelhantes, bem como para a geração de novos dados nessas regiōes.

\section{AGRADECIMENTOS}

Os autores agradecem o suporte financeiro da pesquisa cedido pelo $\mathrm{CNPq}$ e IEPA e o apoio do LAQ/SEMA. A FAPESP, por manter a linha de pesquisa em aeração de corpos de água junto à EESC/USP. Essas instituiçôes, em conjunto, permitem a integração de conhecimento relevante às tomadas de decisão vinculadas à qualidade de água.

\section{REFERÊNCIAS}

CHAPRA, S. C. Surface Water-Quality Modeling. McGraw-Hill. Texas, EUA. 844 p. 1997.

CUNHA, A. C. Monitoramento, Parâmetros e Modelos de Qualidade da Água. MacapálAP: Secretaria de Estado do Meio Ambiente - AP. 83 p. 2000.

CUNHA, A. C; CUNHA, H. F. A. \& SIQUEIRA, E. Q. Water Pollution Survey in Rivers of the State of Amapá-Brazil. In: V Workshop Ecolab, Nov., 19-25. Macapá-AP/Brazil. p 315-323. 2000a.

CUNHA, A . C., BARBOSA Jr.; A. SCHULZ, H. E. Revista Amapá Ciência e Tecnologia. "Processos de Transferência de Massa Através da Interface Ar-Agua: Uma Revisão Descritiva". Período: Abril. Vol. 2, N. 1, pp 20-42. Local: UNIFAP. Macapá-AP. 2000b.

CUNHA, A. C.; SIQUEIRA, E. Q. \& CUNHA, H. F. A.: "Processos de Avaliação das equaçôes de previsão do coeficiente de reaeração no modelo QUAL2E para a modelagem de oxigênio dissolvido: estudo de caso no Ribeirão do Feijão (São Carlos-SP”. Revista AP C\&T. Abril. V. 2, n. 1, $p$ 90-111. Local: UNIFAP. Macapá-AP. 2000c.

CUNHA, A. C.; CUNHA, H. F. A. \& SIQUEIRA, E. Q. "Diffuse Pollution Survey in Rivers of Southeast of Amapá State - Brazil". In: $5^{\text {th }}$ International Conference on Diffuse/Nonpoint Pollution and Watershed Management, Milwaukee, Wisconsin, Proceedings, EUA, June, 10-15. CD-ROM. 2001.

CUNHA, A. C. "Levantamento de Parâmetros Físico-químicos e Hidráulicos para a Avaliação 
da Qualidade da Agua em escoamentos naturais - Desenv. do Distrito Industrial na Bac. do Rio Matapi”. Rel. Na. p/ CNPq/IEPA. MacapáAP, Set., 58p. 2001

CUNHA, A . C. \& CUNHA, H. F. A.: "Monitoramento de Águas Superficiais em Rios Estuarinos do Estado do Amapá sob Poluição Microbiológica. Boletim do Museu Paraense Emílio Goeldi, Série Ciências da Terra (Volume Especial ECOLAB). 2002a.

CUNHA, A . C., et al.: "Approaches to Evaluation of Self-purification in Estuarine Rivers of Southeast of Amapá State - Brazil. In: ABEQUA VIII CONGRESSO DA ASSOCIAÇÃO BRASILEIRA DO QUATERNÁRIO:Período. Local: Mariluz, Imbé - Rio Grande do Sul. 2002b.

CUNHA, A. C. \& COUTO, A.(Orgs). Diagnóstico Rápido Participativo da Bacia do Igarapé da Fortaleza-AP. SETEC/GEA. 55p. 2003.

LAKHAN, V. C. Ed.. Modeling and simulation of the coastal system. In: Applications in Coastal Modeling. Elsevier Oceanography Series, n. 49, pp. 17 - 41. 1989.

LUNG, SENG-WU. Water quality modeling. Vol III: Application to Estuaries. CRC Press, Inc.USA. 194 p. 1993.

METCALF \& EDDY, Inc. Wastewater Engineering: Treatment, Disposal and Reuse. $3^{\mathrm{a}}$ ed. McGraw-Hill, series in Water Res.and
Envir. Engineering, New York.1334 p. 1991.

McCUTHEON,S.C.; FRECH,R.H: Water quality modeling: transport and surface exchange in rivers. v. 1.Series Edit. CRC Pres. Inc. Boca Raton, Florida. EUA. 334p. 1989.

SCHULZ, H.E. Alternativas em Turbulência, Impresso pela EESC/USP, Editora RIMA, São Carlos, S.P. 2001.

SCHULZ, H.E. O Essencial em Fenômenos de Transporte, Impresso pela EESC/USP, Editora RIMA, São Carlos, S.P. 2003.

SIQUEIRA, E. Q. Aplicação do Modelo de Qualidade de Água (QUAL2E) na Modelação de Oxigênio Dissolvido no Rio Meia Ponte (GO). São Carlos-SP. Dissertação (Mestrado) - SHS Escola de Engenharia de São Carlos, USP-SP. 90p. 1996.

SIQUEIRA, E. Q; CUNHA, A. C. O Coeficiente de Reoxigenação no Modelo QUAL2E: Metodologia de Previsão. In: $19^{\circ}$ CONGRESSO BRASILEIRO DE ENGENHARIA SANITÁRIA E AMBIENTAL, Foz do Iguaçú, Paraná, 14 a 19 set. Anais. 1997.

SIQUEIRA, E. Q; CUNHA, A. C. "Reoxygenation coefficient in model QUAL2E: Prediction methodology". Int. Stormwater and Urban Water Syst. Modeling Conf. Monog. 9 in the Series, Proc. of the Conference on
Stormwater and Urban Systems Modeling, Toronto, Ontario, Guelph. Edited by Willian James. Computational Hydraulics International (CHI). Período 24-25 de fevereiro de 2000. pp. 153-160. 2001 .

SILVA, M.S.; KOSUTH, P. 2001 - Comportamento das vazões do rio Matapi em 27.10.2000. In: CONGRESSO DA ASSOCIAÇÃO BRASILEIRA DE ESTUDOS DO QUATERNÁRIO, 8. Imbé-RS. Resumos, ABEQUA, p. 594-596.

VELZ, C. J. Applied Stream Sanitation. A Wiley-Interscience Publication. Second Edition. Michigan, EUA. 799 p. 1984.

\section{Endereço para correspondência:}

Alan Cavalacanti da Cunha SQS 3 I 3, BI. E - Apt 202 70382-050 - Brasília - DF - Brasil Tel.: (6I) 245-8082

E-mail: accunha@mct.gov.br

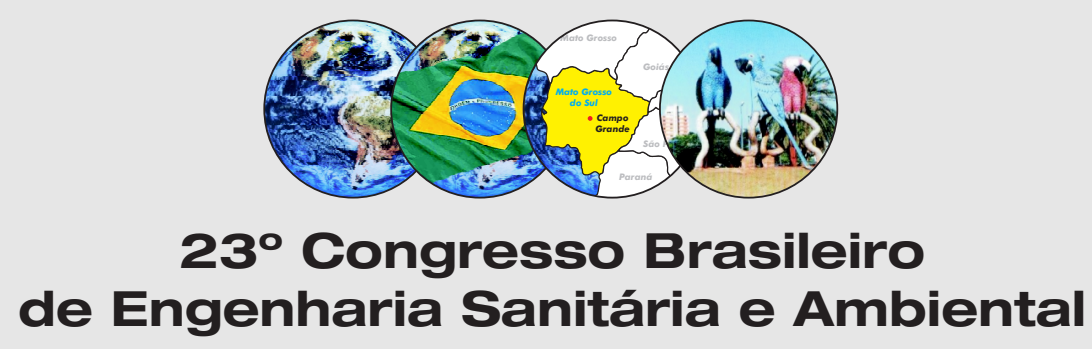
Saneamento Ambiental no Braisl: Utopia ou Realidade?

Data: 18 a 23 de setembro de 2005

Local: Centro de Exposições Albano Franco Campo Grande - MS 